\title{
Sorption study of organic contaminant on raw and modified clay materials
}

\author{
N. Dammak ${ }^{1,2, a}$, N. Fakhfakh ${ }^{1,2}$, S. Fourmentin ${ }^{3,4}$ and M. Benzina ${ }^{1,2}$ \\ 1 University of Sfax, 3029 Sfax, Tunisia \\ 2 Laboratory of research Water, Energy and Environment - code: AD-10-02, National School of Engineers \\ of Sfax, BP. 3038, Sfax, Tunisia \\ 3 Université Lille Nord de France, 59000 Lille, France \\ 4 ULCO, UCEIV, 59140 Dunkerque, France
}

\begin{abstract}
The adsorption of volatile organic compound VOC (o-xylene) was studied by a static headspace coupled to gas chromatography in natural and intercalated clay. Vapor-solid adsorption isotherms of $o$-xylene were measured at $20^{\circ} \mathrm{C}, 30^{\circ} \mathrm{C}$ and $40^{\circ} \mathrm{C}$. Clay was modified with hexadecyl trimetyl ammonium bromide (HDTMA). Absolute values of the amounts of $o$ - xylene adsorbed in intercalated clay were about eighteen times higher than natural clay.

The adsorption isotherm were analysed with Langmuir, Freundlich, Langmuir-Freundlich and Toth models. LangmuirFreundlich model describes well the equilibrium adsorption data. The evaluation of thermodynamic parameters presents an exothermic and spontaneous adsorption process.
\end{abstract}

\section{INTRODUCTION}

Volatile organic compounds (VOCs) are organic substances characterized by their high vapor pressure at ambient temperature and their low boiling point [1]. Many VOCs are hazardous to human health and the environment. Adsorption is one of the most practical methods for separating and recovering VOCs from industrial gas streams [2]. $O$-xylene was selected as a VOC model since it was known to be among the most harmful VOCs [3].

In the past several decades, extensive research has been conducted to develop innovative and promising adsorbent materials for dealing with the treatment problem of contaminated industrial effluents. Natural Tunisian clays are very abundant materials with a low cost and porous texture. Such characteristics make them of capital interest for a possible use in the adsorption of VOCs for their removal from waste gases [4].

In this work, natural clay was modified with the cationic surfactants, HDTMA, to increase its sorptive capabilities on single VOC component. The adsorption isotherms of $o$-xylene on the modified clay materials showed that intercalation of HDTMA could significantly improve the $o$-xylene adsorption, indicating that intercalated materials have the better capacities to adsorb VOC than natural clay materials. Thus, HDTMA can be used to modify clay to improve its sorption capability. A successful response to this synthetic challenge was given by several authors who prepared organobentonites by using cations of alkylammonium for the adsorption of VOCs $[5,6]$.

\section{EXPERIMENTAL}

\subsection{Materials}

$O$-xylene $(98 \%)$ obtained from Fluka Chemical and used without further purification, was chosen as model

a e-mail: dammak.nes@gmail .com compound in this study. The clay material used in this study was taken from Jebel Sbih deposits located in the south of Tunisia from the area of Skhira. For intercalation we use Hexadecyltrimetylammonium bromide obtained from fluka Analytical.

\subsection{Preparation of intercalated clay}

Natural clay (NC) with a cationic exchange capacity (CEC) of 0.85 mmol.g ${ }^{-1}$, was purified. The Na saturated clay was prepared by the treatment of the $<2 \mu \mathrm{m}$ fraction with $\mathrm{NaCl}$ solution by leaving the material in agitation during $24 \mathrm{~h}$ with a $\mathrm{NaCl}$ solution $\left(1 \mathrm{~mol} \mathrm{~L}^{-1}\right)$ for three times. After complete exchange, the sample underwent several dialyses until the complete elimination of chloride, confirmed by the $\mathrm{AgNO}_{3}$ test.

Organoclay (OC) was prepared by dispersing the cationic surfactant (HDTMA), equal to twice the CEC of the clay, into $\mathrm{Na}$ saturated clay under stirring at $80{ }^{\circ} \mathrm{C}$ for $10 \mathrm{~h}[3,7]$. Then, the suspension was washed three times to remove any excess surfactant, dried at $90{ }^{\circ} \mathrm{C}$. Afterwards, the $\mathrm{OC}$ was ground with a mortar and particles of size less than $63 \mu \mathrm{m}$ were collected for the VOC adsorption.

\subsection{Characterisation methods}

To determine the various species constituting the clay materials, a scanning electron micrograph (SEM; Model MEB LEO 438VP equipped with EDS system) was used. Normative mineral composition was calculated from the quantitative chemical analysis obtained by X-ray powder diffractometer (Rigakud-Max 2200 model). FTIR spectra were acquired on a Bruker Spectra.

\subsection{Adsorption experiments}

The adsorption experiments were carried out using the batch equilibration technique. A mass of adsorbent 
Table 1. Elemental analysis of NC and OC.

\begin{tabular}{cccccccc}
\hline & $\mathrm{Si}$ & $\mathrm{Al}$ & $\mathrm{C}$ & $\mathrm{O}$ & $\mathrm{Ca}$ & $\mathrm{Fe}$ & $\mathrm{Mg}$ \\
\hline $\mathrm{NC}$ & 42.13 & 13.34 & 9.29 & 25.54 & 2.91 & 3.39 & 2.13 \\
$\mathrm{OC}$ & 40.54 & 12.92 & 17.8 & 21.83 & 0.91 & 3.34 & 1.73 \\
\hline
\end{tabular}

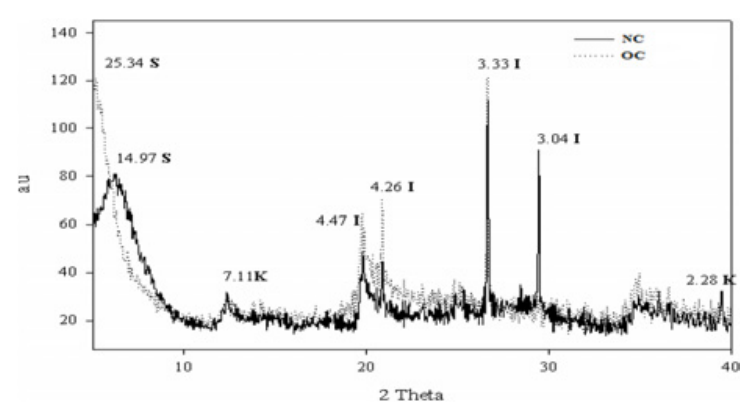

Figure 1. Diffraction of X-ray of NC and OC.

material (200 mg of NC or 10mg of OC) was introduced into a vial of $22 \mathrm{~mL}$. It was covered with glass wool to avoid direct contact with $o$-xylene. The last one with a concentration of $10000 \mathrm{ppm}$ was introduced in variable amounts $(1,2,4,6,8,10$ and $12 \mu \mathrm{L})$. The suspensions were mixed on a rotary tumbler for $24 \mathrm{~h}$ at desired temperature $\left(20,30\right.$ and $\left.40^{\circ} \mathrm{C}\right)$. The adsorbed quantities were determined by calculation of concentration of $o$-xylene in the supernatant with static headspace coupled to gas chromatography.

\section{RESULTS AND DISCUSSION}

\subsection{Physical properties of the clays}

Energy dispersion spectrum (EDS) showed increase in carbon counts due to substitution of surfactant with long carbon chain (Table 1). In addition a considerably decrease in oxygen, aluminium, silica and calcium amounts in OC. Diminution of silica was due to purification of clay and elimination of many silica oxides. Aluminum differences occurred mainly on the amount of tetrahedral aluminium layer [8]. Calcium decrease indicated that the interlayer cation in the smectite component was made of $\mathrm{Ca}^{2+}$ [9].

The XRD patterns of the NC and OC are given in Figure 1. The spectrum shows that this clay is composed mainly of smectite $(\mathrm{S})$ by the appearance of peaks at $14.97 \AA$, kaolinite $(\mathrm{K})$ by the appearance of peaks at $7.11 \AA$ and illite (I) wich is prouved with pe aks at $4.47,4.26$, 3.33 and $3.04 \AA[3,6]$. The peak of smectite in NC was $14.97 \AA$, and it expanded to $25.34 \AA$ for OC. Thus, the basal space was increased.

As shown in Figure 2, the characteristic absorption band at $3622 \mathrm{~cm}^{-1}$ is assigned to the stretching vibration of $\mathrm{AlOH}$ and $\mathrm{SiOH}$ and band at $3416 \mathrm{~cm}^{-1}$ was due to the stretching vibration of $\mathrm{H}_{2} \mathrm{O}$ proved the smectitic nature of clay. The attributions of absorption in the range of $470-1120 \mathrm{~cm}^{-1}$ can were due to $\mathrm{Si}-\mathrm{O}-\mathrm{Si}$ and $\mathrm{Si}-\mathrm{O}-$ $\mathrm{Al}$ bending and stretching [10]. In addition to this, the infrared spectra of OC showed a strong bands at 2920 and $2850 \mathrm{~cm}^{-1}$ attributed to asymmetric and symmetric

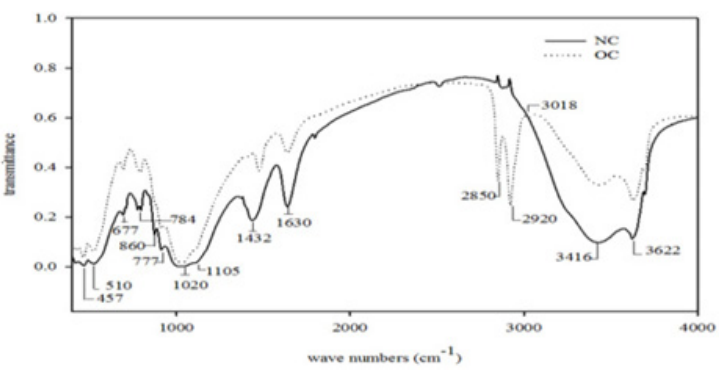

Figure 2. FTIR spectra of NC and OC.

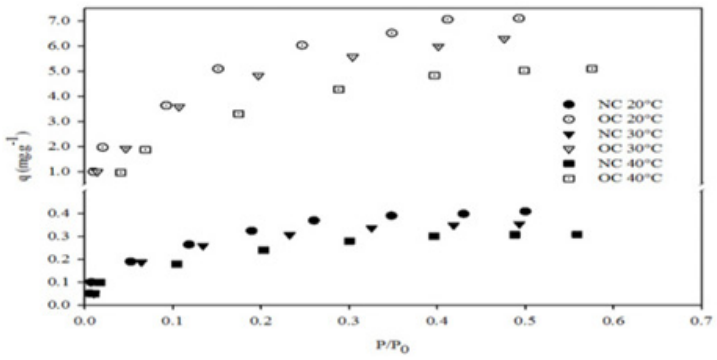

Figure 3. Adsorption isotherms of $\boldsymbol{o}$-xylene on NC and OC (20, $\left.30,40^{\circ} \mathrm{C}\right)$.

stretching vibrations of $\mathrm{C}-\mathrm{H}$ groups and the peak around $3018 \mathrm{~cm}^{-1}$ was assigned to the anti-symmetric stretching modes of the trimethyl ammonium head group of HDTMA [10]. However, after exchange treatment, quaternary ammonium salt apparently entered the interstitial spaces of montmorillonite and was adsorbed on its mineral surfaces.

\subsection{Adsorption isotherms}

The effect of temperature on adsorption of $o$-xylene onto $\mathrm{OC}$ and $\mathrm{NC}$ was investigated at 20,30 and $40^{\circ} \mathrm{C}$. The experimental results (Figure 3) showed that adsorption capacity of $o$-xylene on $\mathrm{NC}$ and $\mathrm{OC}$ decreased from 0.476 to $0.356 \mathrm{mg} . \mathrm{g}^{-1}$ and from 8.765 to $7.299 \mathrm{mg} . \mathrm{g}^{-1}$ respectively with increasing temperatures from 20 to $40^{\circ} \mathrm{C}$, indicating the exothermic nature of VOC adsorption on clay. This slight change could be related to the higher collision frequencies at higher temperature and therefore lower adsorption capacity. Thus, $20^{\circ} \mathrm{C}$ was chosen as the best temperature for the removal of VOCs in the subsequent study.

The isotherms show that the intercalation of HDTMA can remarkably improve the $o$-xylene adsorption of smectite. For example, at temperature of $20^{\circ} \mathrm{C}$, the adsorption capacity of $o$-xylene on NC is $0.476 \mathrm{mg} \cdot \mathrm{g}^{-1}$, and is 18.42 times the value of OC, $8.765 \mathrm{mg} \cdot \mathrm{g}^{-1}$. Our results showed also that the removal of $o$-xylene increased with the increase of the pressure ranges $\left(\mathrm{P} / \mathrm{P}_{0}\right)$ due to the free reactive sites available for the adsorption of $o$-xylene until saturation. However, the adsorbed amount (q) was higher at high pressure ranges (Figure 3 ) due to the larger driving forces for mass transfer at higher pressure. These forces increased the loading capacity of the studied clay samples [11]. Furthermore, the saturation of the surface adsorption sites was favoured due to the higher pressure 
Table 2. Fitted parameters of four models to the experimental data of $\boldsymbol{o}$-xylene isotherm on $\mathrm{NC}$ and $\mathrm{OC}$ at $20^{\circ} \mathrm{C}$.

\begin{tabular}{lccccccccc}
\hline \multicolumn{7}{c}{ Langmuir $q=q_{0} K_{L}\left(P / P_{0}\right) /\left(1+K_{L}\left(P / P_{0}\right)\right)$} \\
\hline \multicolumn{7}{c}{ Organo clay } \\
$\mathrm{q}_{0}$ & $\mathrm{~K}_{L}$ & $\mathrm{R}^{2}$ & $\chi^{2}$ & $\mathrm{q}_{0}$ & $\mathrm{~K}_{L}$ & $\mathrm{R}^{2}$ & $\chi^{2}$ & \\
\hline 0.476 & 12.195 & 0.990 & 0.098 & 8.765 & 8.855 & 0.996 & 0.415 \\
\hline \multicolumn{7}{c}{ Freundlich $q=K_{F}\left(P / P_{0}\right)^{\frac{1}{n}}$} \\
\hline $\mathrm{K}_{F}$ & $\mathrm{n}$ & $\mathrm{R}^{2}$ & $\chi^{2}$ & $\mathrm{~K}_{F}$ & $\mathrm{n}$ & $\mathrm{R}^{2}$ & $\chi^{2}$ \\
\hline 0.182 & 2.909 & 0.987 & 0.023 & 420.950 & 2.663 & 0.980 & 0.432 \\
\hline \multicolumn{7}{c}{ Langmuir-Freundlich $q=q_{0}\left(b\left(P / P_{0}\right)\right)^{n} /\left(1+\left(b\left(P / P_{0}\right)\right)^{n}\right)$} & \\
\hline $\mathrm{q}_{0}$ & $\mathrm{~b}$ & $\mathrm{n}$ & $\mathrm{R}^{2}$ & $\chi^{2}$ & $\mathrm{q}_{0}$ & $\mathrm{~b}$ & $\mathrm{n}$ & $\mathrm{R}^{2}$ & $\chi^{2}$ \\
\hline 0.536 & 3.551 & 1.815 & 0.999 & 0.013 & 9.341 & 4.543 & 1.413 & 0.999 & 0.104 \\
\hline \multicolumn{7}{c}{ Toth $q=q_{0} K_{T}\left(P / P_{0}\right) /\left(1+\left(K_{T}\left(P / P_{0}\right)\right)^{t}\right)^{\frac{1}{t}}$} & & \\
\hline $\mathrm{q}_{0}$ & $\mathrm{~K}_{T}$ & $\mathrm{t}$ & $\mathrm{R}^{2}$ & $\chi^{2}$ & $\mathrm{q}_{0}$ & $\mathrm{~K}_{T}$ & $\mathrm{t}$ & $\mathrm{R}^{2}$ & $\chi^{2}$ \\
\hline 0.731 & 25.438 & 0.476 & 0.998 & 0.020 & 10.500 & 11.218 & 0.700 & 0.998 & 0.154 \\
\hline \multicolumn{7}{c}{}
\end{tabular}

Table 3. Thermodynamic parameters at $20^{\circ} \mathrm{C}$.

\begin{tabular}{ccccc}
\hline clay & $\mathrm{K}_{L}$ & $\Delta \mathrm{G}^{0}\left(\mathrm{~kJ} \cdot \mathrm{mol}^{-1}\right)$ & $\Delta \mathrm{H}^{0}\left(\mathrm{~kJ} \cdot \mathrm{mol}^{-1}\right)$ & $\Delta \mathrm{S}^{0}\left(\mathrm{~J} \cdot \mathrm{mol}^{-1} \mathrm{~K}^{-1}\right)$ \\
\hline $\mathrm{NC}$ & 18.325 & -7.085 & -25.390 & -30.407 \\
$\mathrm{OC}$ & 8.333 & -5.165 & -11.609 & -1.034 \\
\hline
\end{tabular}

of $o$-xylene. The isotherm data were fitted to four models described in Table 2 by non-linear regression.

Where $\mathrm{q}$ is the equilibrium adsorption capacity $\left(\mathrm{mg} . \mathrm{g}^{-1}\right) ; \mathrm{P}$ is the vapor pressures of $\operatorname{VOC}(\mathrm{Pa}) ; \mathrm{P}_{0}$ is the saturated vapor pressures of VOC $(\mathrm{Pa}) ; \mathrm{q}_{\mathrm{m}}$ is the maximum adsorption capacity $\left(\mathrm{mg}^{-1} \mathrm{~g}^{-1}\right) ; \mathrm{K}_{\mathrm{L}}$ is Langmuir constant; $\mathrm{K}_{\mathrm{F}}$ and $\mathrm{n}$ are Freundlich constants; $\mathrm{b}$ Langmuir-Freundlich constant; $\mathrm{K}_{\mathrm{T}}$ and $\mathrm{t}$ are Toth constants. The parameters obtained and the corresponding correlation coefficients $\mathrm{R}^{2}$ and $\chi^{2}$ are summarized in Table 2 .

$$
\chi^{2}=\sum \frac{\left(q-q_{m}\right)^{2}}{q_{m}} .
$$

Where $\mathrm{q}$ and $\mathrm{q}_{m}$ are experimental and calculated equilibrium capacity, respectively. All the data demonstrate almost perfect agreement with Langmuir-Freundlich and Toth models. Toth model over estimated the adsorption of $o$-xylene since the $o$-xylene adsorbed amount always increases with pressure. Thus, the LangmuirFreundlich model fitted best the $o$-xylene adsorption isotherms. However, the Langmuir- Freundlich model is an empirically development of Langmuir equation which is suitable to describe the adsorptive behaviour of homogeneous surfaces, and the Freundlich isotherm which endorses the heterogeneity of the surface. This result suggests that $o$-xylene is adsorbed by different ways on the surface of the natural and OC.Thus, for $o$-xylene, the interaction with the clay can occur between the surface of the clay and the molecule of $o$-xylene or between methyl group of $o$-xylene and the adsorption clay sites [12].

\subsection{Thermodynamic studies}

The adsorption capacities of $o$-xylene on both NC and OC suggest that the interaction of $o$-xylene and clays is exothermic in nature. The thermodynamic parameters such as change in free energy $\left(\Delta \mathrm{G}^{0}\right)$, enthalpy $\left(\Delta \mathrm{H}^{0}\right)$, and entropy $\left(\Delta S^{0}\right)$, were calculated from the slope and intercept of van't Hoff plots of $\ln K_{L}$ vs $1 / T$.

$$
\begin{gathered}
\Delta \mathrm{G}^{0}=-\mathrm{R} \mathrm{TLnK}_{\mathrm{L}} \\
\ln \mathrm{K}_{\mathrm{L}}=\frac{\Delta \mathrm{S}^{0}}{2.303 \mathrm{R}}-\frac{\Delta \mathrm{H}^{0}}{2.303 \mathrm{R}}\left(\frac{1}{\mathrm{~T}}\right) .
\end{gathered}
$$

Where $\mathrm{R}$ is the gas constant and is equal to $8.314 \mathrm{~J}_{\mathrm{mol}} \mathrm{mol}^{-1}$, $\mathrm{K}_{L}$ the equilibrium constant obtained from Langmuir equation and $\mathrm{T}$ is the temperature $(\mathrm{K})$. The thermodynamic parameters for o-xylene adsorption on $\mathrm{NC}$ and $\mathrm{OC}$ are presented in Table 3. The negative values of $\Delta G^{0}$ indicate the spontaneous nature of o-xylene adsorption. The negative value of $\Delta \mathrm{H}^{0}$ which are $-25.39 \mathrm{~kJ} . \mathrm{mol}^{-1}$ for $\mathrm{NC}$ and $-11.61 \mathrm{~kJ}^{\mathrm{mol}}{ }^{-1}$ for $\mathrm{OC}$ confirms the exothermic nature of adsorption. The negative value of $\Delta S^{0}$ indicates a decrease in disorder of o-xylene adsorption. Generally, the absolute magnitude of the change in free energy for physisorption is between -20 and $0 \mathrm{~kJ} . \mathrm{mol}^{-1}$; chemisorption has a range of -80 to $-400 \mathrm{~kJ} . \mathrm{mol}^{-1}$ [13]. The results obtained are -7.08 and $-5.17 \mathrm{~kJ} \mathrm{~mol}^{-1}$ at $20^{\circ} \mathrm{C}$ for $\mathrm{NC}$ and $\mathrm{OC}$, respectively. Considering that these values are in the typical standard free energy range for physisorption, one can conclude that $o$-xylene adsorption on NC and OC mainly physically.

\section{CONCLUSION}

The surface of natural clay is not a more effective adsorbent for the removal of organic compounds from gaz stream. However, natural clay may be modified with organic cations (HDTMA) in a manner that significantly improves its capability of sorption.

The results of present investigation indicate that natural clay and organo clay prepared from low-cost 
natural material have suitable adsorption capacity of $o$ xylene. organo clay showed a higher adsorption capacity toward $o$-xylene than natural clay. The isotherm data were well represented by the Langmuir-Freundlich model. Thermodynamic constants were also evaluated using equilibrium constants changing with temperature. The negative value of $\Delta \mathrm{G}^{0}$ at $20^{\circ} \mathrm{C}$ indicated spontaneity and the negative values of $\Delta \mathrm{H}^{0}$ and $\Delta \mathrm{S}^{0}$ showed the exothermic nature and decrease in disorder of $o$-xylene adsorption, respectively.

\section{References}

[1] P. Hunter, and S.T. Oyama, Wiley, New York (2000).

[2] M. Guillemot, and all., Ind. Eng. Chem. Res. 46, 4614-4620 (2007).

[3] H. He, et al., J. Theo K, Appl. Clay Sci. 31, 262-271 (2006).
[4] I. Jarraya, and all., Chem. Geol. 275, 1-8 (2010).

[5] S.H. Lin, and M.J. Cheng, Waste Manag. 22, 595-603 (2002).

[6] C.Y. Ryu, and S.D. Yeo, J. Ind. Eng. Chem. 16, 441-447 (2010).

[7] Z. Li, and W.T. Jiang, Thermochem. Acta. 483, 58-65 (2009).

[8] S.J. Chipera, and D.L. Bish, Clays and Clay Minerals. 49, 398-409 (2001).

[9] H.L. Hong, and all., Appl. Clay Sci. 42, 292-299 (2008).

[10] Darder, M., Colilla, M., Ruiz-Hitzky, E., Appl. Clay Sci. 28, 199-208 (2005)

[11] F. Qu, and all., J. Hazard. Mater. 170, 7-12 (2009).

[12] H. Zaitan, and all., J. Hazard. Mater. 153 852-859 (2008).

[13] Y. Yu, and all., J. Colloid Interface Sci. 242 (2) 288 (2001). 